\title{
A Multi-purpose Weather Forecast Model for the Mondsee Catchment
}

\author{
Hermann $\mathrm{Klug}^{1}$ and Liviu Oana ${ }^{2}$ \\ ${ }^{1}$ IFFB Geoinformatics - Z_GIS, University of Salzburg, Austria · hermann.klug@sbg.ac.at \\ ${ }^{2}$ Computer Science Department, West University of Timișoara, Romania
}

Full paper double blind review

\begin{abstract}
In the course of climate change, extreme weather events and their consequences are likely to increase in the next decades. To enable publicly available predictions preceding an event, we operate an Advanced Research Weather Research \& Forecasting (WRF-ARW) limited area model to ensure pro-active mitigation strategies before the start of a storm event. To demonstrate the actual model performance for multiple stakeholders, we compared the prediction with publicly available measurements from nearby stations recorded during the extreme event, starting in the evening of October 22nd, 2014 in the Mondsee catchment. In the beginning, the model prediction highly underestimated the rainfall at most of the weather stations. However, the prediction accuracy increased from 54 to 30 hours in advance to the event. For the Mondsee weather station located inside the catchment, the predictions 30 and 6 hours in advance had an accuracy of $-32 \%$ and $-28 \%$, respectively. However, the prediction was challenged by extremely unstable weather conditions. Nevertheless, the prediction forecasted an event where flooding was a very likely consequence, considering the spatial-temporal amount of rainfall predicted. Thus, an early warning message to responsible stakeholders would have been appropriate for pro-active mitigation action in this case.
\end{abstract}

\section{Introduction}

Extreme events, such as heavy solid and liquid precipitation, are expected to increase in the Alps in future (DOBLER et al. 2013). From previous events of the last decades, flooding and heavy snow loads caused stress to the environment, infrastructure, and people in the Mondsee catchment and its surroundings (SWIERCZYNSKI et al. 2013). To avoid further unpreparedness for such kinds of disastrous events, pro-active mitigation planning and action is required to adapt against these impacts on short notice. The standard compliant methodological and technical infrastructure, as for instance outlined by KLUG \& KMOCH (2014), enables an Early Warning System based on the Sensor Web Enablement concept, as described by BRÖRING et al. (2011). An in situ installed monitoring system provides information on local environmental conditions (KLUG et al. 2014). This enables spreading dedicated alert messages to experts and stakeholders, starting three days in advance of an expected event (KLUG \& KMOCH 2015).

GI Forum - Journal for Geographic Information Science, 1-2015.

(C) Herbert Wichmann Verlag, VDE VERLAG GMBH, Berlin/Offenbach. ISBN 978-3-87907-558-4.

(C) ÖAW Verlag, Wien. ISSN 2308-1708, doi:10.1553/giscience2015s600. 
With advancing and continuously growing computing power, numerical weather prediction became more focused on severe weather forecast and nowcasting applications. Especially European limited area prediction systems like the INCA-CE (Integrated Nowcasting through Comprehensive Analysis - Central Europe) provide short period and high-resolution predictions. INCA-CE integrates dense observations and satellite data for improving the precipitation forecast accuracy (STEINHEIMER \& HAIDEN 2007). Moreover, INCA-CE products are user-oriented and are viewed as a "proto-type of demand-side scientific research and development, bridging the gap between science and application" (KANN et al. 2012). Other operational integrated weather prediction and alert systems are operated at national weather administrations. However, many of them lack (free) public access; among them, for instance, the Romanian National Weather Administration implementation SIMIN (the Integrated System for Meteorological Surveillance, Forecast and Alert in Romania) (MARINEL et al. 2004).

With this manuscript we propose a high spatial-temporal resolution, and a publicly accessible Early Warning System on precipitation. We analysed a flood event that started on October 22nd, 2014, and we compare the forecast with measurements from weather stations in and around the Mondsee catchment. We hypothesise that the prediction accuracy of the Advanced Research Weather Research \& Forecasting (WRF-ARW) is strong enough to support early warning to those in need to protect infrastructure and the environment.

\section{Materials and Methods}

\subsection{The Mondsee Catchment}

The $248 \mathrm{~km}^{2}$ Mondsee catchment, close to the Austrian city Salzburg, is located at the border between the European Alps and the hilly alpine foreland with a dozen of mid-sized lakes. The grassland and forest dominated catchment is characterised by a very dense river system of approximate $2 \mathrm{~km} / \mathrm{km}^{2}$ (490 km rivers and ditches), embedded in steep slopes and heavy soils causing fast surface runoff, especially during extreme weather events. Due to the fast response time, villages like Thalgau along the Fuschler Ache, or St. Lorenz close to Lake Mondsee are at risk of being flooded. During extreme events wide floodplains trigger nutrient runoff, causing a water quality challenge for Lake Mondsee. The current trophic status of Lake Mondsee is oligo-mesotrophic, but it repeatedly failed to reach the 'good ecological status' requested by the European Water Framework Directive (MILDNER et al. 2013, UMWELTBUNDESAMT 2013).

\subsection{The October 2014 Heavy Rainfall Event}

From the evening of October 22nd, 2014 a low-pressure centre developed in the Balkan area. It produced heavy rainfall events across central and south-eastern Europe, affecting the Mondsee catchment located at the edge of the Alpine / pre-Alpine area. With its lowest altitude at $478 \mathrm{~m}$, and the highest altitude at the Schafberg elevating $1780 \mathrm{~m}$ asl (only $3 \mathrm{~km}$ south of the lowest point), the Mondsee catchment consists of an orographic wall, locally amplifying the mentioned precipitation. 


\subsection{The High Resolution Early Warning System}

We use the WRF-ARW High Resolution Early Warning System (HREWS) developed and maintained at the West University of Timisoara. The WRF-ARW model is an open source software package developed at The Mesoscale and Microscale Meteorology (MMM) Division of the National Center for Atmospheric Research (NCAR) (WANG et al. 2015). It is a flexible and scale independent atmospheric modelling system, used in meteorological research and numerical weather predictions. Physical atmospheric processes are the basis for real-data simulations, e.g. interpolating primary data, or already computed meteorologycal and terrestrial data, into the simulation domain.

The HREWS input data is the Global Forecast System (GFS) model assimilating additional data from World Meteorological Organisation surface synoptic observations (WMO SYNOP) weather stations. It forecasts numerous weather related parameters, among them precipitation and snowfall, every 6 hours.

We run the WRF-ARW model on two separate computer machines:

- An InfraGrid Cluster on which the data pre- and post-processing, as well as data assimilation is performed.

- A Bluegene supercomputer executing the WRF-ARW core on 1024 quad-core PowerPC microprocessors and 4 TB of RAM.

\subsection{Experiment Design}

We predicted the October 2014 event in real-time using the WRF-ARW limited area model with the HREWS ConTroL system configuration. As input data we used the National Center for Environmental Prediction (NCEP) GFS weather forecast system, and we initialised the WRF model three times, each time closer to the beginning of the event (at 54 hours, 30 hours, and 6 hours before the event).

The meteorological data taken from GFS are available in a 0.5 degrees horizontal resolution. Besides the meteorological data, WRF also uses the following static geographic data:

- Digital Elevation Model: GTOPO-30 including slope, orographic length, orographic asymmetry, and variance of sub-grid-scale orography,

- Land Use: USGS 24-category Land Use,

- Soil data: Global 5 minutes United Nation FAO soil dataset in 16 categories,

- Albedo: monthly average value from NCEP.

We did not use any additional data assimilation methodology during the model setup. We only used the downscaled GFS model forecast with the following simulation domain configuration:

- Horizontal grid-point resolution: $3.5 \mathrm{~km}$,

- Vertical pressure levels: 28,

- $\quad$ East-west extent: 500 grid points,

- North-south extent: 340 grid points.

To validate the precipitation forecast accuracy, we compared the results with measurements from ten weather stations in and around the Mondsee catchment. Publicly available precipitation recordings were obtained from OGIMET (http://www.ogimet.com). 


\section{Results}

\subsection{The Weather Station Measurements}

The 24 hours recordings (from 22.10.2014, 18:00 UTC to 23.10.2014, 18:00 UTC) from the weather stations in and around the Mondsee catchment show the precipitation differences at the pre-Alpine / Alpine border (Figure 1). While the hilly area to the north received less precipitation, the Alpine edge crossing centrally through the Mondsee catchment from east to west shows an increase in precipitation to the southern part. The highest precipitation observations of $122 \mathrm{~mm}$ were reported from the St. Wolfgang weather station. Further south to the Enns valley we observed decreasing precipitation rates; $31 \mathrm{~mm}$ observed in Aigen/Ennstal, and $75 \mathrm{~mm}$ in Bischofshofen.

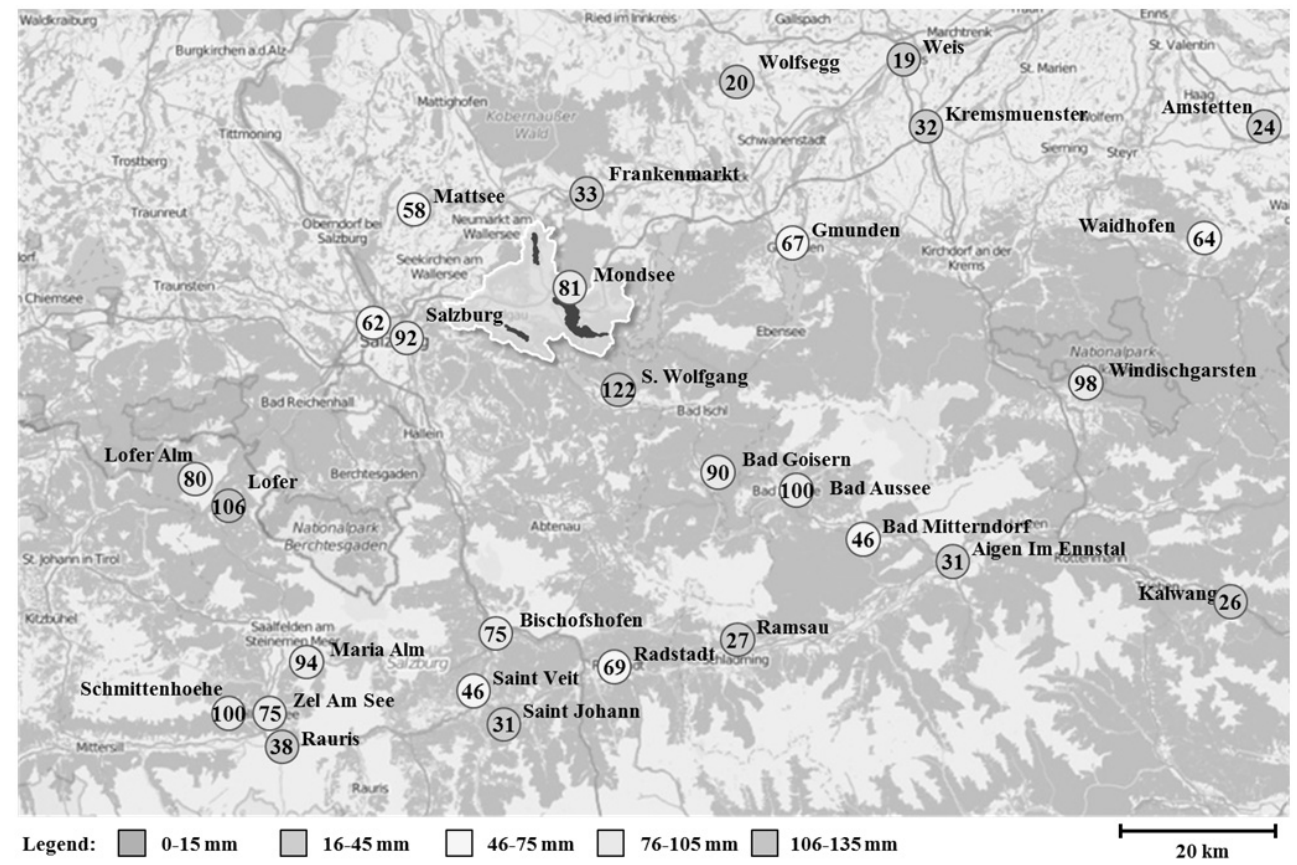

Fig. 1: 24 hour accumulated precipitation at weather stations in and around the Mondsee catchment between 22.10.2014, 18:00 UTC and 23.10.2014, 18:00 UTC

\subsection{The WRF-ARW Results}

The predictions of accumulated precipitation are visualised in three time steps in Figure 2: 54 hours, 30 hours, and 6 hours in advance to 22.10.2014, 18 UTC. The predicted total accumulated precipitation in 24 hours after the start of the event, compared to the observations at the weather stations, is listed in Table 1. The amount of precipitation predicted 54 hours before the start of the event is less than what was actually observed for all of the stations listed. Only for Lofer (50 km south-west of Mondsee) and Bad Aussee (50 km 
south-east of Mondsee) higher precipitation rates are predicted, but not for St. Wolfgang, located only $15 \mathrm{~km}$ south-south-east to Mondsee. As shown by the percentage values in Table 1, the predictions become closer to the observed value the closer the event is approaching.
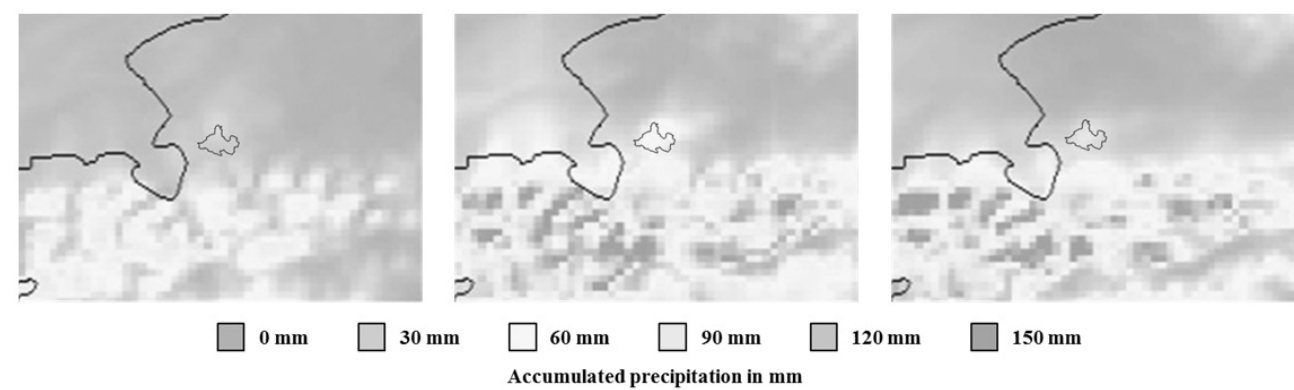

a) 54 hours

b) 30 hours

c) 6 hours

Fig. 2: Total accumulated precipitations between 22.10.2014, 18:00 UTC to 23.10.2014, 18:00 UTC

Table 1: Observed and predicted precipitations for the ten selected stations in relation to the time until the event

\begin{tabular}{|c|c|c|c|c|}
\hline Station & $\begin{array}{l}\text { Observed } \\
\text { pp. }\end{array}$ & a) 54 hours & b) 30 hours & c) 6 hours \\
\hline Mondsee & $81 \mathrm{~mm}$ & $21 \mathrm{~mm}(-74 \%)$ & $55 \mathrm{~mm}(-32 \%)$ & $58 \mathrm{~mm}(-28 \%)$ \\
\hline Lofer & $106 \mathrm{~mm}$ & $60 \mathrm{~mm}(-34 \%)$ & $144 \mathrm{~mm}(+36 \%)$ & $90 \mathrm{~mm}(-15 \%)$ \\
\hline Salzburg - Freisaal & $92 \mathrm{~mm}$ & $16 \mathrm{~mm}(-83 \%)$ & $48 \mathrm{~mm}(-48 \%)$ & $50 \mathrm{~mm}(-46 \%)$ \\
\hline Salzburg - Flughafen & $62 \mathrm{~mm}$ & $17 \mathrm{~mm}(-73 \%)$ & $56 \mathrm{~mm}(-10 \%)$ & $41 \mathrm{~mm}(-34 \%)$ \\
\hline Frankenmarkt & $33 \mathrm{~mm}$ & $22 \mathrm{~mm}(-34 \%)$ & $42 \mathrm{~mm}(+26 \%)$ & $27 \mathrm{~mm}(-17 \%)$ \\
\hline Mattsee & $58 \mathrm{~mm}$ & $22 \mathrm{~mm}(-62 \%)$ & $37 \mathrm{~mm}(-37 \%)$ & $30 \mathrm{~mm}(-49 \%)$ \\
\hline Saint Wolfgang & $122 \mathrm{~mm}$ & $20 \mathrm{~mm}(-83 \%)$ & $63 \mathrm{~mm}(-48 \%)$ & $52 \mathrm{~mm}(-57 \%)$ \\
\hline Kufstein & $109 \mathrm{~mm}$ & $11 \mathrm{~mm}(-90 \%)$ & $30 \mathrm{~mm}(-73 \%)$ & $29 \mathrm{~mm}(-73 \%)$ \\
\hline Bad Goisern & $90 \mathrm{~mm}$ & $20 \mathrm{~mm}(-78 \%)$ & $49 \mathrm{~mm}(-46 \%)$ & $59 \mathrm{~mm}(-35 \%)$ \\
\hline Bad Aussee & $100 \mathrm{~mm}$ & $69 \mathrm{~mm}(-31 \%)$ & $142 \mathrm{~mm}(+42 \%)$ & $128 \mathrm{~mm}(+28 \%)$ \\
\hline
\end{tabular}

\section{Discussion}

The WRF-ARW model prediction 54 hours before the event failed to predict the extreme weather event for most of the stations in and around the Mondsee catchment at an acceptable accuracy of $\pm 20 \%$, compared to the measurements at the weather stations used for validation. Only the two weather stations Lofer and Bad Aussee could have indicated a flood event 54 hours prior to the event, due to higher precipitation rates. All other predic- 
tions underestimated the observed measurements (Table 1). However, the increase in predicted precipitation rates from the first to the second forecast (30 hours in advance to the event) indicates a likely occurrence of an extreme event. Previous events have shown that $50 \mathrm{~mm} /$ day or more (like for Bad Aussee and St. Wolfgang in this case) caused flooding, as observed on October 23rd, 2014. These values correspond well to the storm alert level red defined by UBIMET (2015). They report warnings when precipitation rates exceed $50 \mathrm{~mm}$ in 24 hours, or $100 \mathrm{~mm}$ in 48 hours. However, a generic definition of a threshold value for a heavy rainfall event or a corresponding alert level red does not make sense, since flooding consequences are based on regional settings and local circumstances, e.g. orography, land use and soil properties and presence of human.

Despite the failed prediction 54 hours in advance to the event, the predicted precipitation increase from 54 to 30 hours before the event could trigger warning messages to e.g. the fire brigade, as described by KLUG \& KMOCH (2015). An alert level orange would indicate the necessity to observe the ongoing weather conditions, to be prepared for a likely upcoming storm event. Even though the forecast achieved a better accuracy 30 hours and 6 hours in advance, compared to the observations, the precipitation rates were nonetheless underestimated. This is a tendency of the WRF-ARW model, as also discussed in other studies, e.g. HONG \& LEE (2009). However, the diverse and pronounced orographic pattern of the case study area, with its hilly foreland and steep slopes in the south, make predictions and observations a general challenge. KLUG \& PRÜLLER (2005) underpin this, and found out that for instance annual precipitation rates change on a $20 \mathrm{~km}$ transect from $800 \mathrm{~mm}$ in the north to $1800 \mathrm{~mm}$ in the south of the Mondsee catchment. Furthermore, we used a GTOPO 30 Arc Second $(1 \mathrm{~km})$ resolution digital elevation model (DEM) in our exercise. A Shuttle Radar Topography Mission (SRTM) 90m DEM is expected to increase information on topography and thus might not only better reflect the orographic differences, but also the prediction accuracy. Without having performed this analysis we do not expect significant differences in results compared to the results in this analysis, since the prediction resolution of the forecast is $3.5 \mathrm{~km}$. However, compared to the usual GFS model with a $50 \mathrm{~km}$ cell size, the prediction power of our exercise increased. This does not even change with the recent modification of the GFS model output cell size of $25-27 \mathrm{~km}$ ( 0.25 degrees lat/lon $)$ in January $2015^{1}$. A comparison of the free of charge GFS model product with the product from the European Centre for Medium-Range Weather Forecasts (ECMWF) ${ }^{2}$ shows that the spatial resolution of the ECMWF model with its $16 \mathrm{~km}$ cell size is better by a factor two, but at the same time the costs for the product for a one year service are $36,825.00 \mathrm{EUR}^{3}$.

The challenge of this exercise is not only the model-based underestimation of events, but also the underlying complex orography and the extreme unstable weather situation for this particular event. While the first could be further improved with, e.g. Monte-Carlo selflearning or genetic algorithms, the two latter environmental parameters are difficult to address, and thus provide the prediction uncertainty for the study area. Nevertheless, the spatial resolution of $3.5 \mathrm{~km}$ cell size provides a more detailed overview than large scale models, as mentioned above, usually provide, but the model results are only as good as the input

${ }^{1}$ http://www.emc.ncep.noaa.gov/GFS/impl.php

${ }^{2} \mathrm{http} / / / \mathrm{www}$. ecmwf.int/en/forecasts/documentation-and-support/key-characteristics-forecastingsystem

${ }^{3} \mathrm{http} / / / \mathrm{www}$. ecmwf.int/en/forecasts/accessing-forecasts/payment-rules-and-options/tariffsexamples\#I 
parameters. However, we have not yet thoroughly discussed input parameter uncertainty and uncertainty modelling as such in detail. A higher resolution land use / land cover map including tailored albedo values to the area of interest and the higher resolution European Soil Map might better reflect the soil-surface physics influencing the convective development and the weather parameters near the vicinity of the ground. Cross-comparisons of dataset and influences on the modelling results have not yet been performed, and thus the consequences of updated spatial information on model outputs are still unclear. Further improvements of prediction results relate to the assimilation of additional observational data using 3D Variational or 4D Variational methods, as used e.g. by JONES \& FLETCHER (2013), or Doppler Radar data, as it is known to improve the precipitation forecasts (SOKOL 2009).

With respect to the research question, whether a prediction 54 or even 72 hours in advance can provide an acceptable accuracy, we need to acknowledge that the forecast results compared to the actual event, starting on October 22nd, 2014, might have been misleading. However, although the WRF model generally underestimated the precipitation, the overall forecast concept could provide early warning for responsible stakeholders based on defined rule sets. One of those rules should ensure triggering of warning messages when predictions show strong precipitation increases, especially between 54 to 30 hours preceding the event. When the last predictions become more comparable to the actual measurements, earlier distributed warnings might be supported or withdrawn respectively. However, we acknowledge that we only analysed one particular event, which might not be enough to underpin the constant prediction power of the model. Especially since we analysed a single unstable weather event, more similar events should be analysed in order to evaluate the average precipitation forecast accuracy.

Having discussed potentials of stand-alone applications (forecast model OR in situ measurements) and benefits of synthesised contemplation of hydro-meteorological events (forecast model AND in situ measurements), we advocate for an even more complex placebased holistic integrated water resources management approach. For example, STRAUSS \& STAUDINGER (2007) have estimated that up to $80 \%$ of the annual total phosphorus load of Lake Mondsee originate from single events in the snow melting period from February to March and occasional two to three heavy rainfall events $\left(>50 \mathrm{~mm} \mathrm{~d}^{-1}\right)$ in summer. Thus, forecasts are not only important for the fire brigade to introduce short-term pro-active mitigation action before the expected start of an event. Farmers could be informed not to fertilise their fields prior to a storm event, since surface runoff could potentially wash out the recently applied nutrients (HUBER 2015). In fact, farmers in the Mondsee catchment already expressed interest in receiving information about 72 hours dry period forecasts to ensure best hay making conditions. Thus, looking into integrated and interdisciplinary holistic landscape approaches, tools and techniques from Geoinformatics could be used for multiple purposes; either for flood or dry period forecasting, whereby we still have to prove the capabilities of the used method for the latter. 


\section{Conclusion}

In conclusion, in this study we compared three forecasts initiated at different times relative to the start of a severe weather event, and concluded that despite an underestimation of precipitation, the model forecast 30 hours preceding the event is accurate enough to predict the flooding, which occurred on October 23rd, 2014. We confirm that further improvements as detailed in the discussion need to be made to increase the forecast accuracy with special attention to flood prediction.

\section{Outlook}

The prediction power of extreme events with respect to flood early warning is hypothesised to increase with an integrated water resources management concept, based on standard compliant methods from, e.g. Open Geospatial Consortium (OGC) and the International Organization for Standardization (ISO), as outlined by KLUG et al. (2014). Further developments should consider directly incorporating local rainfall measurements into the prediction model, and coupling them with a self-learning algorithm to improve prediction power. Furthermore, real-time changing soil moisture conditions providing information on spatiotemporal infiltration capacities should be incorporated, since these are considered important for flood probability modelling (CZIGÁNY et al. 2010). The consequences of surface runoff during storm events compared to the infiltration rate could then be modelled in cloud based hydrological modelling toolkits, e.g. compliant with the Open Modelling Interface (OpenMI) (CASTRONOVA et al. 2013a, CASTRONOVA et al. 2013b, KNAPEN et al. 2013). Spatial-temporal raster maps in a Web Coverage Service would then provide further spatial decision support regarding local consequences of a storm event. Spatial statistics on hydrological modelling results could provide vulnerability hot spots as a place-based indication of immediately required mitigation action. During the storm event, discharge measurements, as e.g. done in the sub-catchment Koppl, can provide near real-time information of water masses passing through the Plainfelder Bach, likely affecting the villages Thalgau (10 $\mathrm{km}$ distance) or St. Lorenz (20 km distance) close to Lake Mondsee. Thus, the WRF-ARW model should incorporate in situ measurements for modelling and forecasting operated in an OGC compliant framework as discussed by KLUG \& KMOCH (2015).

\section{Acknowledgement}

The authors acknowledge the West University of Timişoara for providing the computing resources on the InfraGRID cluster and BlueGene supercomputer, without which the conducted research would not have been possible. 


\section{References}

Bröring, A., Echterhoff, J., Jirka, S., Simonis, I., Everding, T., Stasch, C., LiAng, S. \& Lemmens, R. (2011), New Generation Sensor Web Enablement. Sensors, 11 (3), 2652-2699.

Castronova, A. M., Goodall, J. L. \& ElaG, M. M. (2013a), Models as web services using the Open Geospatial Consortium (OGC) Web Processing Service (WPS) standard. Journal of Environmental Modelling \& Software, 41 (0), 72-83.

Castronova, A. M., Goodall, J. L. \& ErCAN, M. B. (2013b), Integrated modeling within a Hydrologic Information System: An OpenMI based approach. Journal of Environmental Modelling \& Software, 39 (0), 263-273.

CzigÁny, S., PirkHOFFer, E. \& GERESDI, I. (2010), Impact of extreme rainfall and soil moisture on flash flood generation. Quarterly Journal of the Hungarian Meteorological Service, 114 (1-2), 79-100.

Dobler, C., BÜrGER, G. \& STÖTTER, J. (2013), Simulating future precipitation extremes in a complex Alpine catchment. Nat. Hazards Earth Syst. Sci., 13, 263-277.

Hong, S.-Y. \& LEE, J.-W. (2009), Assessment of the WRF model in reproducing a flashflood heavy rainfall event over Korea. Atmospheric Research, 93 (4), 818-831.

Huber, M. (2015), Erfassung, Dimensionierung und Gestaltung von Gewässerrandstreifen im Mondseeeinzugsgebiet. Thesis. Interfaculty Department of Geoinformatics - Z_GIS. University of Salzburg, Salzburg, 99 S.

Jones, A. S. \& Fletcher, S. J. (2013), Chapter 13 - Data Assimilation in Numerical Weather Prediction and Sample Applications. In: KleISSL, J. (Ed.), Solar Energy Forecasting and Resource Assessment. Academic Press, 1, 319-355.

Kann, A., Pistotnik, G. \& BiCA, B. (2012), INCA-CE: a Central European initiative in nowcasting severe weather and its applications. Adv. Sci. Res., 8, 67-75.

Klug, H. \& KMOCH, A. (2014), A SMART Groundwater Portal: An OGC web services framework for hydrology to improve data access and visualisation in New Zealand. Computers and Geosciences, 69, 78-86.

KLUG, H. \& KMOCH, A. (2015), Operationalizing environmental indicators for real time multi-purpose decision making and action support. Journal Ecological Modelling, 295, 66-74.

Klug, H., KмосH, A. \& Juhasz, C. (2014), Drahtlose Echtzeitanalysen von Phosphorausträgen bei klimatischen Extremereignissen. In: Strobl, J., BlaschKe, T., GRIESEBNER, G. \& ZAGEL, B. (Hrsg.), Angewandte Geoinformatik 2014. Beiträge zum 26. AGITSymposium in Salzburg. Wichmann, Berlin/Offenbach, 548-557.

Klug, H. \& PRÜller, S. (2005), Die Modellierung des Niederschlages im Einzugsgebiet Mondsee. Unveröff. Projektbericht im Rahmen des Interreg IIIa Projektes "SeenLandWirtschaft".

KnAPEn, R., JANSSEn, S., RoOsenschoon, O., VerWeiJ, P., DE Winter, W., UiterwiJK, M. \& WIEN, J.-E. (2013), Evaluating OpenMI as a model integration platform across disciplines. Journal of Environmental Modelling \& Software, 39 (0), 274-282.

Marinel, I., IVAnovici, V., Cordoneanu, E., BAnciU, D., Apostu, A. \& Ford, B. (2004), SIMIN - The Integrated System for Meteorological Surveillance, Forecast and Alert in Romania. 20th International Conference on Interactive Information and Processing Systems (IIPS) for Meteorology, Oceanography, and Hydrology, 17. 
Mildner, J., Friedl, M., Reichmann, M. \& JohAm, B. (2013), Ergebnisbericht Qualitätselement Phytoplankton - GZÜV 2012 Oberösterreich. Amt der Oberösterreichischen Landesregierung, D. U. u. W., Abteilung Oberflächengewässerwirtschaft/Gewässerschutz. Klagenfurt, KIS Kärntner Institut für Seenforschung GmbH, 119 S.

SOKOL, Z. (2009), Effects of an assimilation of radar and satellite data on a very-short range forecast of heavy convective rainfalls. Atmospheric Research, 93 (1-3), 188-206.

STEINHEIMER, M. \& HAIDEN, T. (2007), Improved nowcasting of precipitation based on convective analysis fields. Adv. Geosci., 10, 125-131.

Strauss, P. \& StAUdinger, B. (2007), Estimating of phosphorus and sediment loads from two main tributaries of lake Mondsee. Schriftenreihe BAW, 26, 18-33.

Swierczynski, T., Lauterbach, S., Dulski, P., Delgado, J., Merz, B. \& Brauer, A. (2013), Mid- to late Holocene flood frequency changes in the northeastern Alps as recorded in varved sediments of Lake Mondsee (Upper Austria). Quaternary Science Reviews, 80 (0), 78-90.

UBIMET (2015), Unwetterarten mit Fokus auf Starkregen. Last update: 08.04.2015, from http://www.uwz.at/at/de/unwetterarten/starkregen.

UMWELTBUNDESAMT (2013), Wassergüte in Österreich - Jahresbericht 2012. BUNDESMINISTERIUM FÜR LAND- UND FORSTWIRTSCHAFT, U. U. W. Wien, $130 \mathrm{~S}$.

Wang, W., Bruyère, C., Duda, M., Dudhia, J., Gill, D., Kavulich, M., KeEne, K., Lin, H.-C., Michalakes, J., Rizvi, S., Zhang, X., Berner, J. \& Smith, K. (2015), User's Guide for the Advanced Research WRF (ARW) Modeling System Version 3.6. National Center for Atmospheric Research, M. M. M. D. 